\title{
La historia de la historia: o una aproximación general a los modos de historiar
}

The history of history: or a general approach to the ways of making history

AURELL, Jaume; BALMACEDA, Catalina; BURKE, Peter; SOZA, Felipe. Comprender el pasado: una historia de la escritura y el pensamiento histórico. Madrid: Akal, 2013, 496 p.

\section{Martha Rodríguez}

mrod@fibertel.com.ar

Docente - Investigadora

Universidad de Buenos Aires

Ladislao Martínez 238 PB - Martínez

1640 - Buenos Aires

Argentina

Palabras clave

Escritura de la historia; Historiografía; Historiadores.

Keywords

Historical writing; Historiography; Historians. 
Escribir una historia de la historiografía que dé cuenta de los esfuerzos realizados durante siglos para escribir la historia es un desafío tan interesante como complejo. Su campo temático y cronológico potencial es tan vasto que toda opción que se escoja implica necesariamente un recorte significativo.

A la amplitud de las fronteras del "territorio del historiador", como lo llamó Emmanuel Le Roy Ladurie, se adicionan las dificultades para delimitar el objeto de estudio (LE ROY LADURIE 1973). ¿Qué incluir dentro de una historia de la historiografía? ¿Todas las obras y autores que explícita o implícitamente esbozaron una imagen del pasado? En ese caso, la dilatación del campo a describir tornaría impensable la empresa, sin contar con que no siempre es sencillo clasificar obras y autores. Por el contrario, entonces, ¿debemos restringirla a la producción escrita de los historiadores profesionales? Esta segunda opción obligaría a prescindir de interesantes formulaciones interpretativas sobre el pasado, sin contar con que mantener ese criterio allende el siglo XIX es por lo menos problemático.

Ciertamente otras prevenciones podrían ser señaladas. ¿Deberíamos enfatizar ideas o aludir a la forma de construcción de los relatos históricos, a aquello que De Certau con agudeza definió como la operación histórica que practican los que escriben sobre el pasado (DE CERTAU 1999)?

¿Qué profundidad temporal darle al objeto? ¿Convendría optar por reconstruir los desarrollos de la historia como actividad intelectual desde la antigua Grecia o, por el contrario, enfatizar lo que - desde diferentes perspectivas - Momigliano o Koselleck denominaron historiografía moderna, haciendo hincapié en las grandes transformaciones que se registraron en ella en los últimos dos siglos (MOMIGLIANO 1992; KOSELLECK 2004)? ¿Sería mejor narrar las raíces de la historiografía y su gradual diferenciación respecto de otros relatos como el mito, la literatura, la tradición oral o el género biográfico, o bien comenzar el recorrido en el momento en que la historia se consolidó como una disciplina, apoyada en la fijación de un canon historiográfico que apelaba a criterios de orden heurístico para validar el conocimiento y a esquemas interpretativos para otorgar sentido a la narración del pasado?

Ninguna de esas opciones generó - ni genera - consenso sin fisuras y ellas mismas se fueron transformando y redefiniendo a lo largo del tiempo en función de climas de época, marcos nacionales e intereses sociales y personales. En cualquier caso, diseñar tan heterogéneo y amplio itinerario enfrenta a quienes intenten embarcarse en esta empresa con dificultades desde el mismo punto de partida.

Frecuentemente, una opción para eludir esos escollos ha sido inclinarse por las aproximaciones acotadas a un/unos autor/es, período/s, tradición/es nacional/es o perspectiva/s. Va de suyo que esa operación declina la aspiración a un cuadro de conjunto de los modos en que los historiadores han ejercido su tarea a lo largo del tiempo. Desde luego, esas prevenciones no fueron obstáculo para que se ensayaran abarcadoras y ambiciosas historias de la historiografía. Por citar solo algunas de la última centuria, en 1916 veía la luz la famosa obra de Benedetto Croce (1916) Teoria e Storia della Storiografia; varias décadas más tarde, Charles Carbonell (1981) publicaba L 'Historiographie y Guy Bourdé 
y Hervé Martin (1983), Les écoles historiques. Más recientemente Daniel Woolf escribió A Global Encyclopedia of Historical Writing (1998), John Burrow (2007) compuso su History of Histories, George Iggers (2008) A global history of modern historiography y, apenas un año atrás, la universidad de Oxford terminó de editar los cinco tomos de su emprendimiento colectivo The Oxford History of Historical Writing (2011/2012)

La reciente publicación de Comprender el pasado: una historia de la escritura y el pensamiento histórico se suma a esas iniciativas. La obra es el resultado del trabajo de cuatro historiadores: Jaume Aurrell, profesor de Teoría de la Historia de la Universidad de Navarra; Peter Burke, profesor del Emmanuel College de la Universidad de Cambridge; Catalina Balmaceda y Felipe Soza, profesores de la Universidad Católica de Chile. Cada uno de ellos proviene de experiencias formativas, tradiciones intelectuales, adscripciones generacionales y contextos nacionales diversos, pero confluyen en una empresa colectiva destinada a reseñar las principales tendencias historiográficas.

El objeto del libro es, pues, describir las prácticas historiográficas que organizaron el trabajo de quienes se dedicaron a escribir sobre el pasado en el largo arco temporal que va de la Antigüedad clásica hasta nuestros días. $Y$, aunque el eje que articula el texto es el análisis del pensamiento histórico occidental, los autores se imponen el esfuerzo de ampliar el estudio a tradiciones mucho menos conocidas - si no desconocidas - en el mundo occidental, como la china o la islámica. Ese mismo espíritu anima el espacio dedicado al 190 análisis de la historiografía latinoamericana, aun con las dificultades que esa denominación supone para dar cuenta de los modos tan diversos de concebir y escribir la historia que ese ámbito encierra. ¿Existe realmente una historiografía latinoamericana? ¿O las características de los casos más estudiados como el mexicano, el brasileño o el argentino operan por generalización como ejemplos de mundos académicos más vastos y heterogéneos?

$\mathrm{Si}$, como sostiene Roger Chartier, las formas de lo impreso, los objetos a través de los cuales les llegan los textos a los lectores, guían y constriñen las lecturas, la elección del formato de manual realizada por los autores es uno de los aciertos de este libro (CHARTIER 1993). A lo largo de sus casi quinientas páginas, invita a asomarse a las variadas formas de representar el pasado desde el mundo clásico, planea sobre las principales tendencias, tradiciones y escuelas historiográficas situándolas en sus contextos históricos, sociales, culturales y políticos $y$, trata, en fin, de presentar los trazos generales de la historiografía. El interés pedagógico y de divulgación de la obra guía su organización. Diseñada en nueve capítulos que siguen un criterio cronológico, "La Antigüedad clásica: Grecia y Roma"; "La Antigüedad tardía: la historiografía cristiana y bizantina"; "La historiografía medieval: siglos IX y XV"; "Del Renacimiento a la Ilustración"; "Más allá de Occidente: islam y China"; "El siglo de la historia: historicismo, romanticismo, positivismo"; "De entresiglos a la década de los setenta: la reacción frente al positivismo"; "Las tendencias recientes: del giro lingüístico a las historias alternativas"; y "La historiografía latinoamericana", cada uno combina la presentación de las tendencias generales con las referencias a los 
historiadores más representativos de cada época, su biografía y fragmentos de algunas de sus obras. Una selección de obras históricas y una amplia bibliografía completan el libro, que consigue convertirse en una suerte de mapa a gran escala, en una aproximación panorámica a la historiografía occidental.

Como lo señalan los autores en el epílogo, "...considerar el pasado como un todo se convierte en algo cada vez más complejo..."; lo mismo ocurre con la historiografía. Sin embargo, hacer el esfuerzo no solo nos permite a nosotros, los historiadores, tomar mayor conciencia de la gramática y de las prácticas que regulan nuestra profesión: ¿acaso cada una de las reconstrucciones del pasado no encierra y expresa un horizonte de expectativas? Si es así, una reflexión en torno a las formas en las que el pasado fue y es interpretado también puede decir mucho a las sociedades presentes embarcadas en la construcción de futuros.

\section{Referencias bibliográficas}

AAVV. The Oxford History of Historical Writing. Oxford: Oxford University Press, 2011/2012. (5 v.)

BOURDÈ, Guy; HERVÈ, Martin. Les écoles historiques. Paris: Seuil, 1983.

BURROW, John. History of Histories. Londres: Penguin, 2007.

CARBONELL, Charles-Olivier. L`Historiographie. Paris: Puf, 1981.

CHARTIER, Roger. Libros, lecturas y lectores en la Edad Moderna. Madrid: Alianza, 1993.

CROCE, Benedetto. Teoria e Storia della Storiografia. Nàpoles, 1916

DE CERTAU, Michel. La escritura de la Historia. México: Universidad Iberoamericana, 1999.

IGGERS, Georg; WANG, Q. Edward. A global history of modern historiography. London: Longman, 2008.

KOSELLECK, Reinhart. historia/Historia. Madrid: Trotta, 2004.

LE ROY LADURIE, Emmanuel. Le territoire de I'historien. Paris: Gallimard, 1973.

MOMIGLIANO, Arnaldo. The classical foundations of Modern Historiography. California: University of California Press, 1992.

WOOLF, Daniel. A Global Encyclopedia of Historical Writing. New York: Garland Pub., 1998. (2 v.) 